\title{
Mensuração de ativos biológicos no manejo das aves de postura: uma proposta a valor justo
}

\author{
Deyvith Alves da Silva
}

Universidade Federal de Rondônia

Brasil

Graduado em Ciências Contábeis pela Universidade Federal de Rondônia.

\section{Deyvison de Lima Oliveira}

Universidade Federal de Rondônia

Brasil

Doutor em Administração pelo PPGA/UFRGS, professor do Departamento de Ciências Contábeis da Universidade Federal de Rondônia - Campus de Vilhena

\section{Sérgio Cândido de Gouveia Neto}

Universidade Federal de Rondônia.

Brasil

Doutor em Educação Matemática pela UNESP, professor do Departamento de Ciências Contábeis da Universidade Federal de Rondônia - Campus de Vilhena.

\section{Sidiney Rodrigues}

Universidade Federal de Rondônia.

Brasil

Mestre em Ciências Contábeis pela FURB-SC, professor do Departamento de Ciências Contábeis da Universidade Federal de Rondônia - Campus de Vilhena.

Artigo submetido em: 27/09/2016

Aprovado em: 05/02/2018

\section{RESUMO}

O objetivo desta pesquisa é propor a mensuração e evidenciação dos ativos biológicos nos grupos estoques e imobilizado a partir da identificação das peculiaridades do manejo das aves de postura, um dos principais setores produtivos do agronegócio nacional. O método adotado é o estudo de caso, e os dados foram coletados mediante entrevistas, observação do manejo e análise de documentos. Com a coleta dos dados na granja foi possível identificar algumas peculiaridades do manejo, que fundamentaram a proposta de evidenciação contábil e da mensuração dos ativos biológicos 'aves de postura'. Levando-se em conta apenas as receitas e despesas da entidade, são consideradas cada fase de vida da ave - de pintinho até o momento de descarte da matriz - e também os produtos agrícolas inclusos no grupo estoques. Limitações e oportunidades de pesquisa constam nas conclusões. 
Palavras-chave: Contabilidade do agronegócio. Aves de postura. Valor justo. Mensuração.

\title{
MEASUREMENT OF BIOLOGICAL ASSETS IN THE HANDLING OF LAYING HENS: A PROPOSAL AT THE FAIR VALUE
}

\begin{abstract}
The objective of this research is to propose the measurement and disclosure of biological assets in the groups 'inventories and fixed assets' starting from the identification of the characteristics of the management of laying hens, one of the main productive sectors of agribusiness. The method used is the case study, and data were collected through interviews, observation on the management, with document analysis of the productive sector. With data collection on the farm it was possible to identify some peculiarities of management, justifying the proposed accounting disclosure and the measurement of biological assets 'laying hens'. Taking into account only the revenues and expenses of the entity are considered each hen life stage - from chick until the time of the matrix discarding - and also agricultural products included in the group inventories. Limitations and research opportunities are contained in the conclusions.
\end{abstract}

Keywords: Agribusiness Accounting. Laying hens. Fair value. Measurement.

\section{INTRODUÇÃO}

O agronegócio tem uma parcela significativa no Produto Interno Bruto (PIB) nacional de acordo com o CEPEA (2013), o que tem fomentado estudos contábeis sobre a mensuração e evidenciação de ativos desde 2009 (MARTINS e OLIVEIRA, 2014; SILVA, MACHADO e MACHADO, 2013). Com a implantação, pelo Comitê de Pronunciamentos Contábeis (CPC), do Pronunciamento 29 houve uma padronização de normas para a contabilidade do agronegócio que migrou para uma regularidade junto as normativas internacionais que eleva as demonstrações a um entendimento mais abrangente.

Considerando a relevância do agronegócio para a economia brasileira e as mudanças no cenário contábil nacional [como a introdução do CPC 29], observa-se uma necessidade de estudos na área do agronegócio (WANDERLEI; SILVA; LEAL, 2012), principalmente, que proponham a mensuração de ativos vivos específicos, por vezes, sem valor de mercado como referência para o valor justo.

No Brasil o crescimento econômico está diretamente ligado ao desenvolvimento de seus setores, e o agronegócio encontra-se entre eles, logo com esse crescimento a ciência contábil torna-se uma aliada no auxílio às entidades, apoiando o processo decisório nas organizações, o crescimento do país e a melhoria na qualidade de vida da população brasileira (FARIA, MONTOVANI e MARQUES, 2010). 
O manejo das aves de postura e seus produtos decorrentes (ovos) têm participação relevante no agronegócio, já que são produtos de elevado consumo das famílias. As aves de postura são consideradas um ativo biológico para a produção, ou seja, esse ativo é destinado para a produção de produto agrícola [a exemplo das árvores frutíferas, o gado leiteiro, os cafezais, entre outros (OLIVEIRA e OLIVEIRA, 2015)], tendo o ovo como principal produto agrícola. Neste caso, as galinhas produtoras dos ovos são consideradas um ativo imobilizado por gerarem para a granja os seus produtos agrícolas. A literatura demanda investigações que enfatizem a adequada mensuração desses ativos biológicos e produtos agrícolas à luz do novo paradigma de mensuração: o valor justo, regulado pelo CPC 29, especificamente, itens 12 e 13.

O objetivo da pesquisa é propor a mensuração e evidenciação dos ativos envolvidos no manejo das aves de postura, nos grupos estoques e imobilizado, a partir do conhecimento das peculiaridades da produção.

Além da introdução, este artigo está estruturado em mais quatro seções: na seção 2 encontra-se o referencial teórico que inclui adoção do CPC 29 no Brasil e ativos biológicos, valor justo, características dos estoques e ativos imobilizados, e avicultura de postura; na seção 3 encontra-se a descrição do método de estudo de caso e coleta de dados; na seção 4 tem-se a apresentação e análise de dados, ciclo operacional, proposta de evidenciação e mensuração dos ativos; as considerações finais constam na seção 5 .

\section{MENSURAÇÃO E EVIDENCIAÇÃO DE ATIVOS BIOLÓGICOS NO BRASIL}

O referencial teórico encontra-se dividido em quatro subseções: a subseção 2.1 traz aspectos conceituais de ativos biológicos e a normativa contábil CPC 29 - Ativo biológico e produto agrícola; em 2.2 está a definição do valor justo e suas peculiaridades; na subseção 2.3 consta a caracterização dos estoques e ativos imobilizados; a subseção 2.4 traz alguns números da avicultura de postura.

\subsection{ADOÇÃO DO CPC 29 E ATIVOS BIOLÓGICOS}

Segundo Martins, Machado e Callado (2014), o tratamento contábil para os ativos biológicos e demais atividades agropecuárias, até a publicação do CPC 29, eram orientados pelos Princípios Fundamentais de Contabilidade (PFC), publicados pelo Conselho Federal de Contabilidade (CFC) onde, por princípio, os ativos, dentre eles os biológicos, eram contabilizados pelo seu custo histórico.

Publicado no Brasil em 2009, o CPC 29 inicia uma nova fase de mensuração de ativos biológicos na história contábil nacional. O referido pronunciamento - tradução do International 
Accounting Standard 41 - Agriculture - iniciou sua vigência no Brasil em 2010 e alcançou mais de duas dezenas de empresas da Bolsa de Valores (BARROS et al., 2012).

O CPC 29 traz como definição de atividade agrícola o gerenciamento da transformação biológica e da colheita de ativos biológicos adicionais, pela entidade. Assim, somente as atividades em que haja o gerenciamento produtivo são abrangidas pelas regras do pronunciamento.

A normativa apresenta conceitos específicos para ativos biológicos e produtos agrícolas. Para os primeiros, o conceito é de planta ou animal vivos; os produtos agrícolas, por sua vez, são aqueles colhidos de ativo biológico da entidade (CPC 29, 2012). Nem sempre a separação entre ativo biológico e produto agrícola é razoavelmente clara, já que em alguns ramos de negócio, a atividade fim precisará ser analisada.

Tem-se como norma no CPC 29 (2012) o dever de reconhecimento de um ativo biológico ou produto agrícola como resultado de benefícios econômicos futuros para a entidade. Deve-se fazer a mensuração desses ativos da entidade a valor justo, confiavelmente, utilizando critérios relevantes para refletir os padrões de mercado (WANDERLEY; SILVA e LEAL, 2012).

\subsection{VALOR JUSTO}

O termo valor justo refere-se ao "valor pelo qual um ativo pode ser comercializado, ou um passivo liquidado, entre partes interessadas, conhecedoras do negócio e independentes entre si, não havendo elementos que pressionem para a transação, ou que caracterize uma transação forçada" (OLIVEIRA; OLIVEIRA, 2015).

$\mathrm{O}$ valor justo se baseia em um procedimento de mudança de valores de ativos trazendo esses a preços de venda atuais como se fossem comercializados na data de hoje à um valor mais significativo e com maior relevância de mercado. Portanto, trazendo a um valor mais próximo da realidade do mercado, seguindo princípios como apuração de mercado de fontes internas e externas, verificando a consistência dos preços, a transparência do processo dentre outros (VICENSI, 2003).

Em normas brasileiras, o valor justo não consegue informar clara e objetivamente o real valor dos ativos biológicos, tendo outra terminologia, que é a expressão valor de mercado. Assim, a adoção do valor justo como método de avaliação tem sido criticada, por ser permeada de subjetividades e carecer de objetividade na definição dos critérios de mensuração, o que poderia possibilitar eventuais gerenciamentos de resultados, especialmente, para ativos 
biológicos sem valor de mercado - como constata-se da literatura (SILVA; NARDI e RIBEIRO, 2015).

O CPC 29 orienta que na contabilização de ativos biológicos deve ser utilizado o valor justo menos a despesa de venda, exceto se não houver possibilidades de uma mensuração segura de ativos (MARTINS e OLIVEIRA, 2014). A mudança na mensuração para o valor justo nos ativos biológicos representa a elevação dos ativos biológicos a valores mais relevantes à contabilização e demonstração do resultado das entidades em conformidade ao mercado, mantendo o valor dos ativos o mais perto possível dos valores reais negociáveis (MARTINS; MACHADO; CALLADO, 2014).

Rech e Pereira (2012) afirmam que, com a implantação do CPC 29 no cenário contábil brasileiro, a nova abordagem de mensuração de ativos e passivos mudou o método de mensuração do antigo e bem mais simples custo histórico para o novo e complexo valor justo. Anteriormente, uma base de mensuração mais objetiva e verificável e, agora, uma base mais relevante para a tomada de decisão, mas com uma necessidade de conhecimento do manejo dos ativos vivos pelo contabilista para elaboração das demonstrações. Tendo em vista que a mensuração dos ativos biológicos ficou mais desafiadora e com melhor orientação a quem necessita utilizar as informações geradas como parâmetro.

Partindo em busca do novo contexto da globalização dos negócios, a contabilidade passou por sérias e importantes mudanças nos últimos anos, levada pelas normativas estabelecidas pelo International Accounting Standard Board (IASB) e no, Brasil, pelo Comitê de Pronunciamentos Contábeis (CPC). As inovações atingiram, também, o agronegócio, pelo qual passou a ser regido, em termos contábeis, pelo IAS 41. No Brasil o seu correspondente normativo é CPC 29 - Ativo Biológico e Produto Agrícola. Ressalta-se que os conceitos e regramentos do CPC 29 alcançam também as pequenas entidades do setor agropecuário.

Silva et al. (2013) relatam que, independente das particularidades do agronegócio, as informações trazidas pelo contabilista podem ajudar na avaliação permanente e sistemática da situação que se encontra o patrimônio das entidades, fornecendo informações gerenciais que atendam à demanda gerencial e também à demanda informacional dos usuários externos. Com as inovações trazidas pelo CPC 29, estimula-se também as pequenas e médias empresas do agronegócio a usufruir das diretrizes do IASB, pois muitas entidades do setor agropecuário enquadram-se em categorias de menor porte e familiares.

Com a implantação do CPC 29 nas entidades agrícolas a troca do custo histórico pelo valor justo, devido às grandes particularidades no setor, provocou várias polêmicas na forma de mensuração e registro de alguns ativos biológicos, como naqueles ativos que não dispõem 
de valor negociável - sendo mensurado pelo valor de uso, com auxílio de técnicas de fluxos de caixa descontados (SILVA et al., 2013).

Pode ocorrer casos em que o valor justo aproxima-se do valor de custo, consta do próprio CPC 29, em seu item 24:

(a) uma pequena transformação biológica ocorre desde o momento inicial (por exemplo as árvores frutíferas brotadas a partir de sementes ou mudas plantadas no período imediatamente anterior ao do encerramento das demonstrações contábeis); ou (b) não se espera que o impacto da transformação do ativo biológico sobre o preço seja material (por exemplo, para o crescimento inicial da plantação de pinos cujo ciclo de produção é de trinta anos) (CPC29, 2009).

Segundo Brito e Ambrozini (2013), a contabilidade do agronegócio obteve um grande salto com a implementação do CPC 29, aplicável desde 2010, que formalizou diretamente a maneira de se contabilizar ativos biológicos e produtos agrícolas, baseando-se na normativa internacional IAS 41.

Martins e Oliveira (2014) afirmam que, na contabilidade, a mensuração se resume à atribuição de valores monetários aos vários itens que compõem o patrimônio de uma entidade, ou seja, determinando em números, o valor dos ativos que a entidade dispõe. Para uma devida mensuração de ativos biológicos precisa-se de um conhecimento da cultura agropecuária a ser mensurada, dadas as particularidades de cada caso.

\subsection{ESTOQUES E IMOBILIZADO NA ATIVIDADE RURAL}

Nos setores de atividades comerciais, industriais e de prestação de serviços (não rurais) a mensuração de estoques inclui todos os valores do custo de aquisição e de transformação, juntamente com os gastos para deixá-los em condições e locais atuais (CPC 16, 2009). Segundo o CPC 16, estoques são os considerados: “a) mantidos para venda no curso normal dos negócios; b) em processo de produção para venda; ou c) na forma de materiais ou suprimentos a serem consumidos ou transformados no processo de produção ou na prestação de serviços".

Os estoques, portanto, são os ativos mantidos para a venda, ou na forma de materiais ou suprimentos à serem consumidos ou transformados no processo de produção ou na prestação de serviços, abrangendo também os ativos biológicos e produtos agrícolas, de acordo com as características da atividade. Na atividade rural, segundo Oliveira e Oliveira (2015), os estoques são os produtos agrícolas gerados de ativos biológicos para produção, produtos agrícolas gerados por ativos biológicos consumíveis e os próprios ativos biológicos consumíveis, que sejam destinados à venda (ou eventual consumo). Assim como no comércio, os estoques da atividade rural encontram-se no grupo 'Ativo Circulante'. 
Como ocorre com os estoques, o Imobilizado, em regra é mensurado nas demais atividades pelo custo de aquisição ou produção - a partir das premissas do CPC 27. São reconhecidos como Ativo Imobilizado, à luz do art. 179 da Lei no 6.404/76:

Os direitos que tenham por objeto bens corpóreos destinados à manutenção das atividades da companhia ou da empresa ou exercícios com essa finalidade, inclusive os decorrentes de operações que transfiram à companhia os benefícios, riscos e controle desses bens (BRASIL, 1976).

O ativo Imobilizado possibilita a geração de benefícios futuros por período, geralmente, superior a um exercício, e pressupõe a possibilidade de mensuração do custo do ativo (IUDÍCIBUS et al., 2013) ou de valor definido por normativas específicas, como ocorre com o valor justo.

Em seu item 44, o CPC 29 apresenta um grupo de ativos com características de Imobilizado, a saber, os biológicos mantidos para produção. Esses ativos são aqueles que, por diversas vezes, possibilitam a colheita de produtos agrícolas ou podem gerar ativos biológicos consumíveis; com essas particularidades os ativos biológicos que têm como função a manutenção das atividades da entidade são considerados ativos imobilizados, por gerarem benefícios em um longo período de tempo (OLIVEIRA e OLIVEIRA, 2015).

Adicionalmente, no tocante ao Imobilizado, o CPC 27 (2012) em seu item 2 traz que “ativos imobilizados são itens tangíveis utilizáveis por mais do que um ano e que sejam detidos para uso na produção ou fornecimento de mercadorias ou serviços, para aluguel ou para fins administrativos". Logo, constata-se que na atividade zootécnica em questão (aves de postura), a galinha se enquadra como ativo imobilizado por fornecer a produção produto agrícola (ovo) para a entidade.

Por analogia, ativos biológicos para a produção são como máquinas para as entidades, pois dão origem aos produtos agrícolas, a exemplo das aves de postura, das árvores frutíferas, dos cafezais, da cana-de-açúcar, dentre outros (OLIVERA e OLIVEIRA, 2015).

\subsection{AVICULTURA DE POSTURA: ALGUNS NÚMEROS}

Em um panorama mundial, de acordo com a Secretaria de Estado e Agricultura e do Abastecimento - SEAB (2013), a produção mundial de ovos em 2011 ficou em torno de 1,220 trilhão de unidades anuais espalhados por todos os continentes do planeta. Nesse contexto, o Brasil, no ano de 2011, obteve a sétima colocação mundial com uma produção crescente com cerca de 40 bilhões de unidades produzidas, que representa cerca de 3,34\% da produção mundial, ficando atrás de países como China, Estados Unidos, Índia, Japão, México e Rússia. 
Em um panorama nacional no ano de 2012, segundo a SEAB (2013), a distribuição da produção de ovos entre regiões do país está distribuída nas seguintes participações: no Sudeste encontra-se o maior número de produtores com cerca de 50,2\% da produção nacional, seguida da região Sul (com 20,1\%), da região nordeste $(15,7 \%)$, da região centro-oeste $(10,3 \%)$ e a região norte, com apenas $3,7 \%$ da produção nacional.

No Brasil, de acordo com Barros (2006), a sociedade vem sendo beneficiada de várias formas com o maior desempenho que o agronegócio vem apresentando desde a década de 1990, com o rápido crescimento na produtividade e com a redução de custos. O consumidor sente um impacto positivo e com isso a ampliação do agronegócio vem crescendo a cada ano.

Essa realidade de crescimento da produção no agronegócio fomenta estudos contábeis em setores específicos do Brasil, que enfatizem propostas de mensuração e evidenciação de ativos biológicos, à luz das normativas em vigor. Nesta linha, esta pesquisa objetiva propor a mensuração e evidenciação dos ativos biológicos nos grupos estoques e imobilizado, a partir da identificação das peculiaridades do manejo das aves de postura.

\section{MÉTODO}

Para se chegar ao objetivo em uma observação científica percebe-se a necessidade de adotar métodos científicos, que particularmente são uma junção de processos ou trabalhos mentais que se fazem necessário em pesquisa (PRODANOV e FREITAS, 2013).

A abordagem da pesquisa é qualitativa, que tem como característica uma realidade que não pode ser quantificada, centrando-se na compreensão e explicação da dinâmica das relações sociais. Adicionalmente, a pesquisa qualitativa tem como característica: objetivação do fenômeno; hierarquização das ações de descrever, compreender, explicar, precisão das relações entre o global e o local em determinado fenômeno; observância das diferenças entre o mundo social e o mundo natural (GERHARDT e SILVEIRA, 2009).

\subsection{ESTUDO DE CASO}

Prodanov e Freitas (2013), afirmam que o estudo de caso se aplica em pesquisas onde as questões se encaixam com perguntas que comecem com 'Como' e 'Por que', também quando o pesquisador possui pouco domínio em relação aos eventos e quando o foco da pesquisa se baseia em fenômenos atuais infiltrados em contexto da realidade.

Portanto, a abordagem metodológica utilizada na pesquisa é o estudo de caso, que tem como unidade de análise uma granja de aves de postura no Cone Sul do Estado de Rondônia. Yin (2010) afirma que, em uma atividade prática investigativa de algo ou acontecimento com certo grau de profundidade que possua relação com a realidade, deve-se considerar o estudo de 
caso como método aplicável. $\mathrm{O}$ estudo de caso tem sido adotado em estudos de ativos biológicos específicos na área contábil (e.g.: MARTINS e OLIVEIRA, 2014; FIORENTIN et al., 2014).

\subsection{COLETA DE DADOS}

Foram utilizados para a coleta de dados entrevistas com perguntas abertas, considerando peculiaridades do manejo das aves de postura e seus produtos agrícolas, observação do ambiente da produção e análise de dados colhidos com o produtor.

Foram feitas quatro visitas na granja. Em duas visitas foram realizadas apenas observação para conhecimento do ambiente granjeiro e da produção. Nas outras duas visitas houve aplicação de entrevistas aplicadas com o produtor, com uma duração aproximada de 15 minutos cada uma. A primeira entrevista visou ao conhecimento sistêmico do processo produtivo, incluindo informações sobre o negócio e os ativos envolvidos; a segunda entrevista teve o objetivo de obter conhecimento do manejo, ciclo operacional, incluindo vida produtiva das aves, mercado dos ativos e produtos envolvidos, dentre outros.

Após a coleta de dados nas entrevistas e na observação do manejo procedeu-se à análise com o intuito de atender ao objetivo geral da pesquisa, a saber: propor a mensuração e evidenciação dos ativos envolvidos no manejo das aves de postura, nos grupos estoques e imobilizado, a partir do conhecimento das peculiaridades da produção.

\section{RESULTADOS E PROPOSTAS}

As galinhas poedeiras são adquiridas ainda pintinhos e ao longo de sua vida se tornam aves, que obtém ganhos com o passar do tempo em decorrência do seu desenvolvimento natural. Esse processo representa as transformações pelas quais passa o ativo biológico que podem ser positivas (crescimento/nascimentos) ou negativas (degeneração/mortes), denominadas respectivamente, ganhos e perdas. Mudanças no valor justo menos despesa de venda do ativo devem ser reconhecidas [em decorrência das transformações] no momento inicial e no final de cada período, sendo os ganhos e as perdas adicionados ao resultado do exercício de acordo com o item 26 do CPC 29 (2009).

O CPC 29, em seu item 15, menciona que para identificar o valor justo de um ativo biológico ou produto agrícola pode ser feito o agrupamento por idade e/ou qualidade, com vistas a sua devida fixação de preços usando atributos significativos identificados no mercado, o que é realizado mediante a proposta apresentada nas subseções seguintes.

\subsection{CARACTERÍSTICAS DO NEGÓCIO}


O produtor da granja pesquisada não possui um manejo padronizado, mas se utiliza da experiência passada entre gerações, e conta com a apoio técnico de um veterinário para o melhor cuidado das aves. A granja se encontra instalada na região desde o final da década de 1990 utilizando basicamente o que foi 'passado de pai para filho'. A mão de obra utilizada envolve 30 colaboradores, incluindo a área administrativa.

Na perspectiva, operacional, para que a produção aconteça, a granja demanda alguns ativos fixos, como: galpões, trato/manejo automatizado, fábrica de ração etc.

Na unidade de análise em questão, no momento da pesquisa, havia 230 mil aves, das quais, 187 mil se encontravam em produção. As demais estavam em crescimento ou descartadas/destinadas à venda para abate.

\subsection{CICLO OPERACIONAL DA PRODUÇÃO DE OVOS}

O ciclo de produção começa quando se compra o pintinho. O valor pago pela unidade é de $R$ \$ 2,90, para a ave de produção dos ovos brancos. O pintinho que se transformará em ave de produção de ovos vermelhos custa aproximadamente R \$3,00 a unidade.

Realizada a compra, o produtor precisa vaciná-los contra doenças recorrentes nas aves, tais como new castle, bronquite, gunboro e boba.

Em média, conforme informações do produtor, as aves comem em torno de 105 gramas de ração por dia, no caso da ave branca e cerca de 110 gramas, para a ave vermelha. Ainda se constata que há um desperdício, em decorrência do mecanismo de tratamento, aproximadamente, de 5\% - como confirma o produtor.

O produtor alega que o custo da ave até a fase de produção está em torno de $\mathrm{R} \$ 7,00$ que, se adicionado à mão de obra e energia elétrica, alcançaria cerca de $\mathrm{R} \$ 10,00$. Observa-se também a contrapartida, que seria o descarte das aves, quando chegam na $90^{\mathrm{a}}$ semana de vida, onde não estão mais aptas a botar como o desejado e são vendidas para frigoríficos a um valor aproximado de: $\mathrm{R} \$ 5,00$ por cada ave vermelha; e $\mathrm{R} \$ 3,33$ cada ave branca.

Assim, são produzidos na granja dois tipos básicos de ovos: o vermelho e o branco. O que diferencia os dois tipos é basicamente o tipo da ave. As aves utilizadas na produção são as das raças Heinsex, Hellin, Loma, White e a Brown.

Quando realizada a compra do pintinho, as vacinas são aplicadas para garantir sua saúde, para que em 120 a 140 dias de vida a ave já esteja apta à produção, com um ovo pequeno e modesto no começo, chamado de ovo industrial, iniciando-se em seguida a produção de ovos normais. O ovo industrial também tem mercado, contudo, apenas os ovos comuns serão considerados na pesquisa para a proposta de mensuração e evidenciação dos ativos. 
A produção dos ovos tem um período de 71 semanas, abrangendo o período que vai da $19^{\mathrm{a}}$ semana até a $90^{\mathrm{a}}$ semana. Da experiência do produtor, observa-se que a ave bota em torno de seis ovos na semana, considerando a granja como um todo, tendo sempre $90 \%$ das aves em produção diária no período entre a $19^{\mathrm{a}}$ e a $50^{\mathrm{a}}$ semana. O rendimento das aves é diminuído, após a $50^{a}$ semana, para $80 \%$ das aves em plena produção diária.

Tem-se de produção diária na granja pesquisada a média 126 mil ovos, o que equivale a 350 caixas, com 30 dúzias cada uma. As aves produzem também diariamente 3.700 quilogramas de esterco, que são vendidos para produtores rurais à, aproximadamente, $\mathrm{R} \$$ 200,00 a tonelada.

\subsection{EVIDENCIAÇÃO DO ATIVO BIOLÓGICO E FORMAÇÃO DE ESTOQUES}

A partir das peculiaridades do manejo das aves de postura, enunciadas acima, apresentase uma proposta de evidenciação do subgrupo ‘Estoques' no Ativo Circulante, considerando os seus produtos agrícolas e o grau decrescente de liquidez para a entidade.

Figura 1 - Plano de contas resumido para os produtos das aves de postura - Estoques

\begin{tabular}{|l|}
\hline Ativo \\
(...) \\
Circulante \\
Estoques \\
Produtos agrícolas \\
$\quad$ Produto agrícola - ovos \\
(-) Ajuste por despesa de venda \\
Produto agrícola - esterco \\
(-) Ajuste por despesa de venda \\
Produto agrícola - aves descartadas \\
(-) Ajuste por despesa de venda
\end{tabular}

Fonte: Dados da pesquisa (2016)

Oliveira e Oliveira (2015) mencionam que os estoques abrangem os produtos agrícolas originados do ativo biológico para produção, produtos agrícolas de ativos biológicos consumíveis e também o próprio ativo biológico destinado à venda. Considerando a literatura mencionada, tem-se no grupo 'Estoques' os produtos agrícolas: ovo, esterco e ave para descarte, que são itens negociáveis da entidade. Neste caso, o ovo é considerado produto principal, e os demais, subprodutos.

Como procedido para os Estoques, apresenta-se na Figura 2 a proposta de evidenciação dos ativos biológicos para produção, no subgrupo do Ativo Não Circulante 'Imobilizado'. Por gerarem benefícios futuros, por período superior a um exercício (IUDÍCIBUS et al., 2013), os 

justo. Revista Unemat de Contabilidade, v. 6, n. 12, 2017.

ativos (aves de postura) são considerados 'Imobilizado', como defende a literatura (MARION, 2014).

Adicionalmente, a ave poedeira se caracteriza como imobilizado por ser um bem corpóreo destinado à manutenção das atividades da entidade, por ser tangível, utilizado por mais de um ano, por transferir à entidade os benefícios, riscos e controle do ativo (OLIVEIRA e OLIVEIRA, 2015; BRASIL, 1976, art. 179). 
Figura 2 - Plano de contas resumido para as aves de postura - Ativo Imobilizado

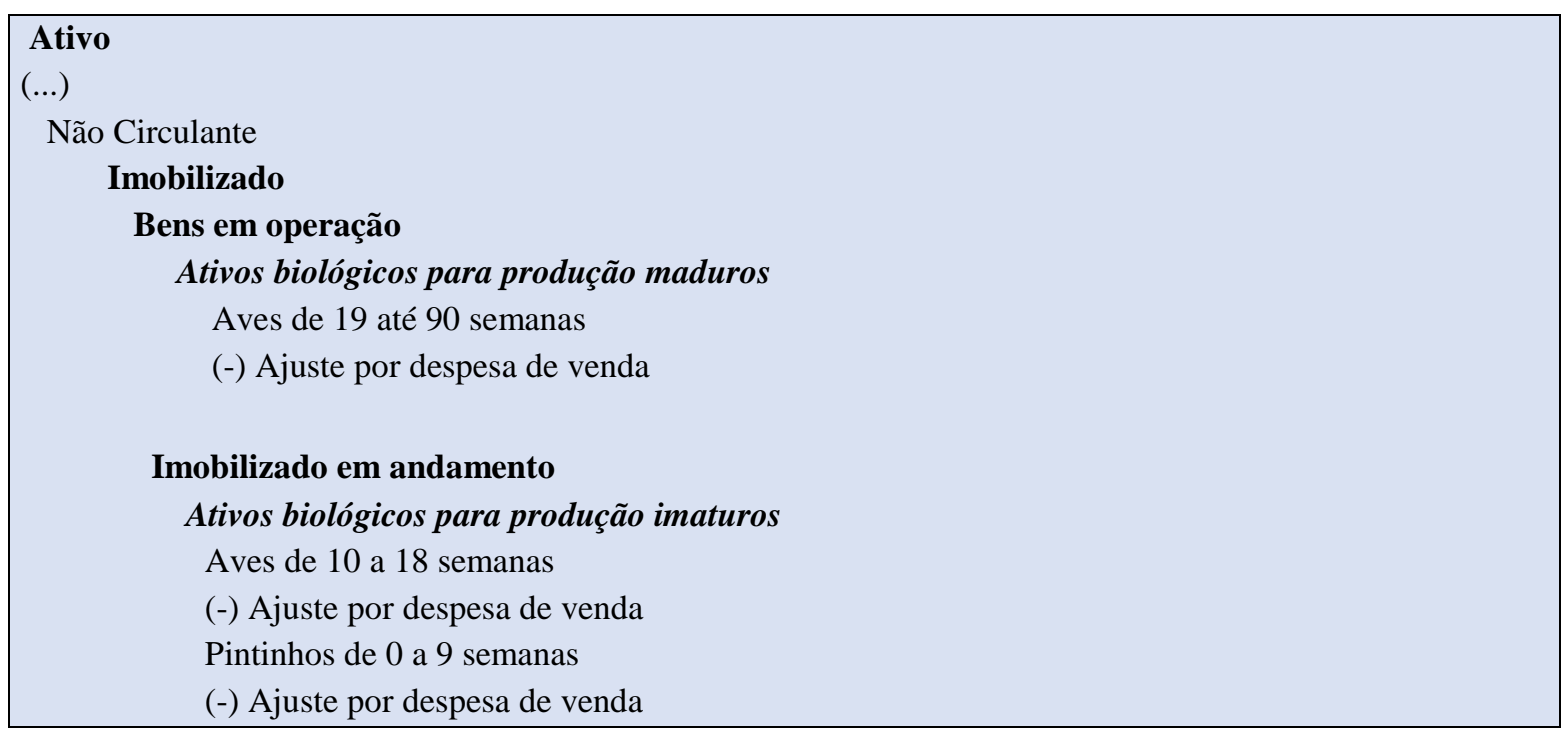

Fonte: Dados da pesquisa (2016).

Os ajustes por despesa de venda utilizados nas Figuras 1 e 2 se referem ao valor com as despesas necessárias à venda do ativo biológico (CPC 29, 2009). Exemplos dessas despesas, especificamente, poderiam ser o frete para a entrega dos ativos, a devida embalagem e também outras despesas atreladas à operação de manejo. A contrapartida desse ajuste é registrada no resultado, como decorrência do reconhecimento de ganhos pelo crescimento natural ou de perdas pela degeneração dos ativos, em respeito ao regime de competência.

\subsection{PROPOSTA DE FLUXO CONTÁBIL}

Com base nas propostas de evidenciação contábil na atividade produtiva de aves de postura e seus produtos (Figuras 1 e 2), nesta seção apresenta-se a proposta de mensuração dos ativos envolvidos, separados em fases produtivas.

São apresentados na Figura 3 dados da produção, referentes aos produtos (ovos) no período de quatro semanas, com vistas ao melhor entendimento do fluxo contábil da mensuração dos Estoques envolvidos na atividade (Figura 4), sendo que os valores neles contidos são apenas estimados, extraídos do mercado regional no momento da pesquisa. Ressalta-se que na proposta de mensuração dos ativos da produção das aves de postura desconsiderou-se a depreciação de equipamentos/máquinas e infraestrutura construída, considerando-se apenas as receitas e as despesas que estão relacionadas ao ativo biológico. 
SILVA, D. A. DA et al. Mensuração de ativos biológicos no manejo das aves de postura: uma proposta a valor justo. Revista Unemat de Contabilidade, v. 6, n. 12, 2017.

Figura 3 - Dados da proposta de mensuração na produção de aves de postura - Estoques.

\begin{tabular}{|c|c|c|}
\hline Registro & Descrição & Valor $(\mathbf{R} \$)$ \\
\hline A & $\begin{array}{l}\text { Registro dos ganhos pela produção de seis ovos por semana de cada ave, num total } \\
\text { de } 24.000 \text { ovos no final das quatro semanas, sendo } 2.000 \text { dúzias a } R \$ 4,00 \text { cada uma }\end{array}$ & 8.000 \\
\hline $\mathrm{B}$ & $\begin{array}{l}\text { Reconhecimento do ajuste por despesa de venda (as despesas com embalagem, } \\
\text { transporte e mão de obra que compõem a venda) }\end{array}$ & 500 \\
\hline $\mathrm{C}$ & Custos/despesas com manejo (composta por ração, luz elétrica e mão de obra...) & 2.800 \\
\hline $\mathrm{D}$ & Venda dos ovos & 8.000 \\
\hline $\mathrm{E}$ & Baixa do ajuste despesa de venda (realização financeira) & 500 \\
\hline $\mathrm{F}$ & Baixa dos estoques mensurados a valor justo & 8.000 \\
\hline G & $\begin{array}{l}\text { Produção de } 450 \text { quilogramas de esterco produzido pelas aves em } 4 \text { semanas, } \\
\text { considerado o valor de } \mathrm{R} \$ 200,00 \text { a tonelada }\end{array}$ & 90 \\
\hline $\mathrm{H}$ & Reconhecimento do ajuste por despesa de venda (esterco) & 20 \\
\hline I & Venda do esterco & 90 \\
\hline $\mathrm{J}$ & Baixa do ajuste despesa de venda do esterco (realização financeira) & 20 \\
\hline $\mathrm{K}$ & Baixa dos estoques mensurados a valor justo (esterco) & 90 \\
\hline $\mathrm{L}$ & Aves descartadas (para venda) & 5.000 \\
\hline M & Reconhecimento do ajuste por despesa de venda (aves descartadas) & 100 \\
\hline $\mathrm{N}$ & Receita de venda por valor acima do mensurado (aves descartadas) & 5.500 \\
\hline $\mathrm{O}$ & Baixa do ajuste despesa de venda (aves descartadas) & 100 \\
\hline $\mathrm{P}$ & Baixa dos estoques mensurados a valor justo (aves descartadas) & 5.000 \\
\hline $1-12$ & Apuração do resultado do período & - \\
\hline
\end{tabular}

Fonte: Dados da pesquisa (2016)

A partir dos dados da Figura 3, um fluxo contábil é apresentado na Figura 4, destacando os três produtos agrícolas na ordem de importância, em que os ovos ficam como principal produto, com maior produção e relevância na entidade. Em seguida está o esterco cuja produção também é diária, porém secundária - gerando uma receita modesta; e por fim tem-se as aves que cessaram sua vida útil produtiva, que são destinadas à venda (transferidas para o estoque). 

justo. Revista Unemat de Contabilidade, v. 6, n. 12, 2017.

Figura 4 - Proposta de Fluxo Contábil de 1.000 Aves - quatro semanas de produção (Estoques).

\begin{tabular}{|c|c|c|c|c|c|}
\hline \multicolumn{6}{|c|}{ ESTOQUES } \\
\hline \multicolumn{6}{|c|}{ Ovos } \\
\hline \multicolumn{2}{|c|}{ Ovos } & & & & \\
\hline \multirow[t]{2}{*}{ (A) 8.000} & \multirow[t]{2}{*}{$8.000(\mathrm{~F})$} & \multirow{2}{*}{\multicolumn{2}{|c|}{ Ganho Produto Agrícola-Ovos }} & \multicolumn{2}{|c|}{ Ajuste Desp. de Venda-Ovos } \\
\hline & & & & (E) 500 & $500(\mathrm{~B})$ \\
\hline \multicolumn{2}{|c|}{ Disponível } & (1) 8.000 & $8.000(\mathrm{~A})$ & & \\
\hline \multirow[t]{2}{*}{ (D) 8.000} & $2.800(\mathrm{C})$ & & & & \\
\hline & $500(\mathrm{E})$ & & & \multicolumn{2}{|c|}{ Desp. Estim. de Venda-Ovos } \\
\hline 4.700 & & & & (B) 500 & $500(2)$ \\
\hline \multicolumn{2}{|c|}{ Receita de Venda-Ovos } & \multicolumn{2}{|c|}{ Despesa com Manejo-Ovos } & \multicolumn{2}{|c|}{ Estoque Vendido-Ovos } \\
\hline (5) 8.000 & $8.000(\mathrm{D})$ & (C) 2.800 & $2.800(4)$ & (F) 8.000 & $8.000(3)$ \\
\hline \multicolumn{6}{|c|}{ Esterco } \\
\hline \multicolumn{2}{|c|}{ Esterco } & \multirow{2}{*}{\multicolumn{2}{|c|}{$\begin{array}{l}\text { Ganho Produto Agrícola- } \\
\text { Esterco }\end{array}$}} & & \\
\hline (G) 90 & $90(\mathrm{~K})$ & & & Ajuste De & da-Esterco \\
\hline \multicolumn{2}{|c|}{ Disponível } & (6) 90 & $90(\mathrm{G})$ & (J) 20 & $20(\mathrm{H})$ \\
\hline (I) 90 & $20(\mathrm{~J})$ & & & & \\
\hline \multicolumn{6}{|l|}{70} \\
\hline & & Desp. Est & Venda-Esterco & Estoque & -Esterco \\
\hline \multicolumn{2}{|c|}{ Receita de Venda-Esterco } & (H) 20 & $20(8)$ & (K) 90 & $90(9)$ \\
\hline (7) 90 & $90(\mathrm{I})$ & & & & \\
\hline \multicolumn{6}{|c|}{ Aves para Descarte } \\
\hline \multicolumn{2}{|c|}{ Aves Descartadas (Estoques) } & \multirow{2}{*}{\multicolumn{2}{|c|}{$\begin{array}{l}\text { Aves em Produção } \\
\text { (Imobilizado) }\end{array}$}} & \multirow{2}{*}{\multicolumn{2}{|c|}{$\begin{array}{l}\text { Ajuste Desp.de Venda } \\
\text { (Aves em Produção) }\end{array}$}} \\
\hline \multirow[t]{2}{*}{ (L) 5.000} & \multirow[t]{2}{*}{$5.000(\mathrm{P})$} & & & & \\
\hline & & $(\mathrm{SI})$ & $5.000(\mathrm{~L})$ & (M) 100 & (SI) \\
\hline \multicolumn{2}{|c|}{ Disponível } & & & & \\
\hline (N) 5.500 & $100(\mathrm{O})$ & \multirow{2}{*}{\multicolumn{2}{|c|}{$\begin{array}{l}\text { Ajuste Desp.de Venda } \\
\text { (Aves Descartadas) }\end{array}$}} & & \\
\hline \multirow[t]{3}{*}{5.400} & & & & & $\mathrm{DO}$ \\
\hline & & $100(\mathrm{O})$ & $100(\mathrm{M})$ & (2) 500 & $8.000(1)$ \\
\hline & & & & (3) 8.000 & $8.000(5)$ \\
\hline \multicolumn{2}{|c|}{$\begin{array}{l}\text { Receita de Venda } \\
\text { (Aves Descartadas) }\end{array}$} & $\begin{array}{r}\text { Es } \\
(\mathrm{Av}\end{array}$ & $\begin{array}{l}\text { Vendido } \\
\text { cartadas) }\end{array}$ & (4) 2.800 & $90(6)$ \\
\hline (10) 5.500 & $5.500(\mathrm{~N})$ & (P) 5.000 & $5.000(11)$ & (8) 20 & $90(7)$ \\
\hline & & & & (9) 90 & $5.500(10)$ \\
\hline & & $\mathrm{Lu}$ & umulado & (11) 5.000 & \\
\hline & & & $5.270(12)$ & 16.410 & 21.680 \\
\hline & & & & (12) 5.270 & 5.270 \\
\hline
\end{tabular}

Fonte: Dados da pesquisa (2016).

Como realizado para a formação dos estoques, alguns dados são apresentados na Figura 5 para a proposta de mensuração dos ativos biológicos para produção no Imobilizado. Esses 
SILVA, D. A. DA et al. Mensuração de ativos biológicos no manejo das aves de postura: uma proposta a valor justo. Revista Unemat de Contabilidade, v. 6, n. 12, 2017.

dados são utilizados para demonstração do fluxo contábil da formação do imobilizado na atividade "aves de postura".

Figura 5 - Dados da proposta de mensuração na produção de aves de postura - Imobilizado.

\begin{tabular}{|c|l|r|}
\hline Registro & \multicolumn{1}{|c|}{ Descrição } & Valor (R\$) \\
\hline A & Aquisição de pintinhos de 0 a 9 semanas, com valor de mercado de R\$ 3,00/un. & 3.000 \\
\hline B & Reconhecimento do ajuste por despesa de venda & 1.000 \\
\hline C & Despesas com o manejo das aves & 1.500 \\
\hline D & Ganhos pelo crescimento das aves & 2.500 \\
\hline E & Reconhecimento do ajuste por despesa de venda (crescimento pintinho 0 a 9) & 700 \\
\hline F & $\begin{array}{l}\text { Mudança de categoria das aves (de pintinho 0 a 9 semanas para ave de 10 a 18 } \\
\text { semanas) }\end{array}$ & 5.500 \\
\hline G & Registro de ganhos pelo crescimento (ave de 10 a 18 semanas) & 1.500 \\
\hline H & Reconhecimento do ajuste por despesa de venda (crescimento - ave de 10 a 18) & 500 \\
\hline I & Despesas com o manejo das aves & 2.000 \\
\hline J & $\begin{array}{l}\text { Mudança de categoria das aves (de ave de 10 a 18 semanas para ave de 19 a 90 } \\
\text { semanas) }\end{array}$ & 7.000 \\
\hline K & Registro de ganhos pelo crescimento (ave de 19 a 90 semanas) & 5.000 \\
\hline L & $\begin{array}{l}\text { Reconhecimento do ajuste por despesa de venda (crescimento - ave de 19 a 90 } \\
\text { semanas) }\end{array}$ & 800 \\
\hline M & $\begin{array}{l}\text { Despesas com o manejo das aves (foram calculadas 71 semanas à um gasto médio } \\
\text { de R\$ 700 semanal) }\end{array}$ & 49.700 \\
\hline
\end{tabular}

Fonte: Dados da pesquisa (2016)

Considerando as fases de crescimento [de pintinho à ave de 19-90 semanas], apresentase na Figura 6 o fluxo contábil do Ativo Imobilizado, que demonstra o tratamento da formação dos ativos biológicos para produção, os ganhos pelo crescimento natural, as despesas estimadas de venda no momento da mensuração e as despesas com o manejo.

O fluxo está estruturado em fases produtivas, abrangendo três períodos: i) aquisição dos pintinhos 0 a 9 semanas; ii) aves de 10 a 18 semanas; iii) aves de 19 a 90 semanas. Desconsiderou-se a apuração do resultado no fluxo da mensuração do Imobilizado (Figura 6).

Com o crescimento das aves, naturalmente, obtém-se ganhos que são debitados na conta 'Pintinho de 0 a 9 semanas' e creditados na conta 'Ganhos', conforme item 26 o CPC 29. Assim, constata-se a necessidade de adotar um fluxo para as fases de crescimento dos ativos biológicos, registrando separadamente os ganhos em cada fase - do pintinho de 0 a 9 semanas de vida, passando pela ave da $10^{\mathrm{a}}$ a $18^{\mathrm{a}}$ semana, e chegando ao ativo em seu estágio maduro, com a ave já em produção, entre a $19^{\mathrm{a}}$ e a $90^{\mathrm{a}}$ semana de vida - que tem um ganho considerável em decorrência de sua atual produção, de acordo com a entidade pesquisada. 

justo. Revista Unemat de Contabilidade, v. 6, n. 12, 2017.

Figura 6 - Proposta de Fluxo Contábil de 1.000 Aves - quatro semanas de produção (Imobilizado).

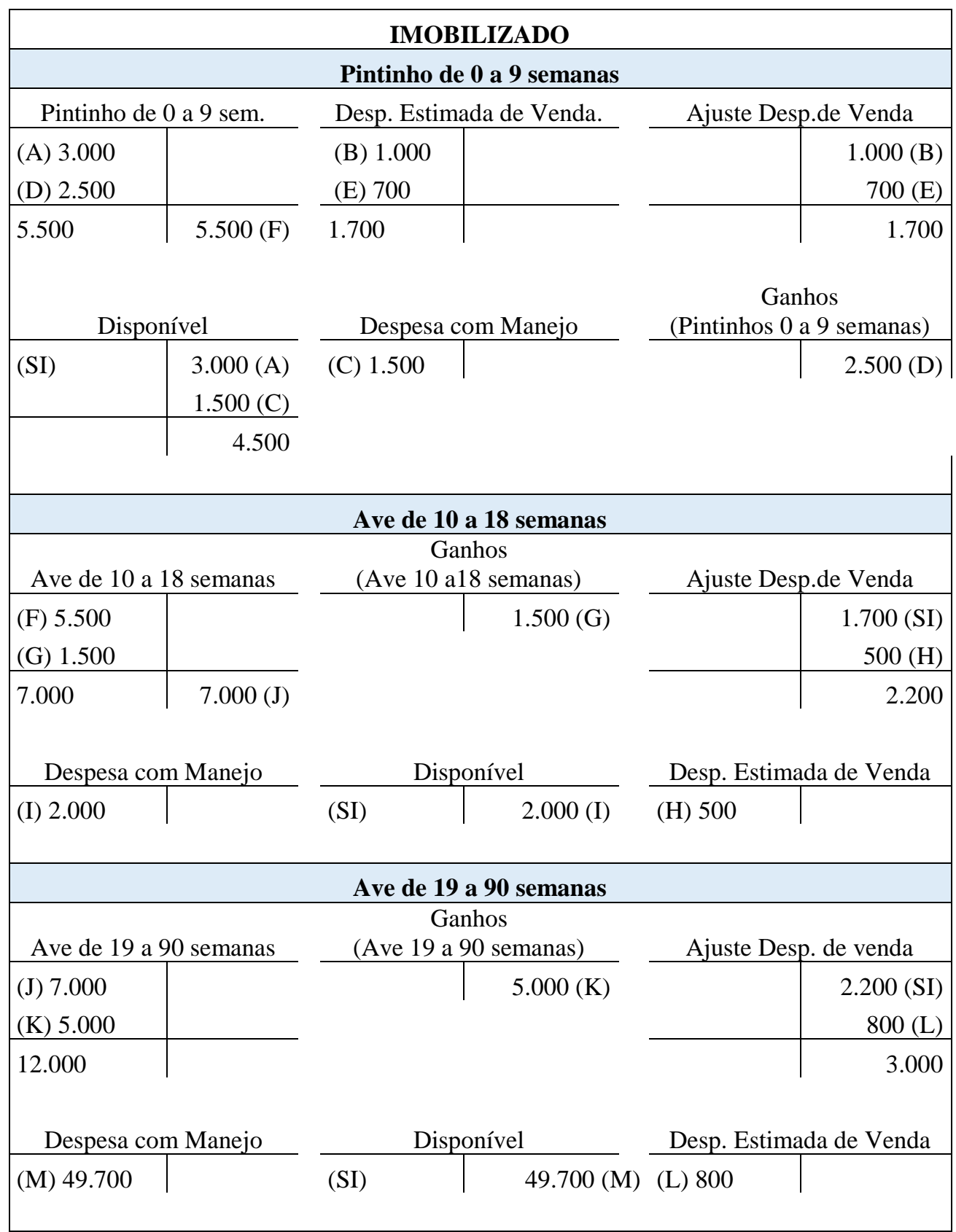

Fonte: Dados da Pesquisa (2016).

Esta forma de reconhecimento contábil está alinhada às diretrizes do CPC 29 e da literatura afim (OLIVEIRA e OLIVEIRA, 2015), principalmente, quanto ao reconhecimento de ganhos pela transformação biológica, à classificação das aves nas suas diferentes fases produtivas e ao reconhecimento dos ativos de acordo com suas características (estoques ou imobilizado).

Adicionalmente, os ganhos reconhecidos para as aves estão em conformidade com o item 26 do CPC 29, que determina que os ganhos e/ou perdas provenientes da mudança no valor justo menos despesa de venda devem ser incluídos no resultado do exercício em que ocorrerem. 
Durante o crescimento do pintinho observam-se gastos com o manejo natural - comuns em qualquer atividade zootécnica - que são levados em consideração no fluxo contábil a cada fase da ave. Esses gastos são inicialmente registrados como custos da produção, e em um segundo momento são reconhecidos como despesas do exercício, quando os ganhos do ativo são registrados. Neste caso, pelo regime de competência, os ganhos do período (pelo crescimento) são confrontados com a despesa de manejo, com o fim de apurar o resultado, que tem caráter econômico (não financeiro) enquanto as vendas não ocorrerem.

$\mathrm{Na}$ fase entre a $19^{\mathrm{a}}$ a $90^{\mathrm{a}}$ semana foi considerado o consumo das 71 semanas de produção; a cada 1.000 aves propõe-se um consumo estimado de $\mathrm{R} \$ 700,00$ de despesas semanais, logo ao longo da sua vida produtiva ter-se-ia $\mathrm{R} \$ 49.700,00$ em despesas de manejo.

Os valores debitados em 'Despesa com Manejo' foram creditados da conta 'Disponível', incluindo-se como despesas: a ração, mão de obra, luz elétrica e vacinas. A conta 'Ajuste de Despesa de Vendas' foi adotada para creditar as estimativas em caso de o produtor vender o seu ativo imobilizado (a ave em formação), nas fases de vida da galinha citadas no presente artigo, considerando gastos com transportes e mão de obra como base, a débito de 'Despesa Estimada de Venda'. Essa abordagem de registros está alinhada ao item 12 do CPC 29, que preceitua: "O ativo biológico deve ser mensurado ao valor justo menos a despesa de venda no momento do reconhecimento inicial e no final de cada período de competência [...]" (destaque nosso).

\section{CONSIDERAÇÕES FINAIS}

O objetivo desta pesquisa é propor a mensuração e evidenciação dos ativos nos grupos estoques e imobilizado a partir das peculiaridades do manejo das aves de postura. Os resultados foram alcançados mediante a proposição de um breve modelo de evidenciação (contas) para os estoques e o imobilizado, bem como de mensuração de produtos agrícolas e ativos biológicos na atividade de manejo das aves de postura.

A proposta de mensuração e evidenciação trazida nos resultados contribui com a mensuração dos ativos a valor justo no manejo das aves de postura considerando as peculiaridades do manejo e a relevância deste setor produtivo no agronegócio brasileiro. A pesquisa contribui com a proposição de um modelo desenvolvido para os ativos biológicos 'aves de postura', contudo, factível de adaptações para aplicação em outros contextos produtivos das atividades zootécnicas, a exemplo da produção de avestruz e outras aves de postura. Pela pesquisa também se confirma a possibilidade de mensurar os ativos biológicos aves de postura e seus produtos com base no valor justo, à luz dos preceitos do CPC 29. 
A pesquisa apresenta limitações, como a ausência de depreciação das estruturas, demandas por maiores detalhamentos nas contas propostas (ex. desconsideração das classes de ovos), que podem ser sanadas no contexto da prática contábil. Igualmente, a aplicação de caso único também é entendida como limitação, contudo, a unidade em análise está entre as maiores da região estudada. Adicionalmente, para as propostas apresentadas foram consideradas somente as receitas e despesas que se relacionam diretamente com os ativos biológicos e seus produtos agrícolas, tendo em vista o objetivo da pesquisa.

Com base nas limitações apresentadas, são oportunas novas pesquisas que tratem de: i) propostas mensuração/evidenciação que considerem o ciclo produtivo completo ( 1 a 2 anos), em forma de estudo horizontal, considerando-se também a depreciação de instalações; e ii) as fontes para informações sobre valor justo dos produtos e ativos biológicos na atividade.

\section{REFERÊNCIAS}

BARROS, G.S. de C. et al. Perspectivas, Desafios e uma agenda para seu desenvolvimento. Agronegócio Brasileiro julho 2006.

BARROS, C. d. C.; SOUZA, F. J. V. d.; ARAÚJO, A. O.; SILVA, J. D. G. d.; SILVA, M. C. d. Impacto do valor justo na mensuração dos ativos biológicos nas empresas listadas na BM\&FBOVESPA. Revista de Contabilidade do Mestrado em Ciências Contábeis da UERJ (online), v. 17, n. 3, p. 41-59, set./dez. 2012.

BRITO, S. S., AMBROZINI, M. A. Impactos da Implementação das Normas Internacionais de Contabilidade Sobre Indicadores Financeiros: Um Estudo das Empresas Brasileiras com Ativos Biológicos. Revista Contabilidade Vista \& Revista, v.29, n.3, p.78-102, jul/set.2013.

BATALHA, M. O. Gestão Agroindustrial. 2. ed. São Paulo: Atlas, 2002.

CEPEA - Centro de Estudos Avançados em Economia Aplicada. PIB Agro CEPEAUSP/CNA. Disponível em: http://cepea.esalq.usp.br/pib/ Acesso em 15.11.2015.

CPC. CPC 16 Estoques. Pronunciamentos técnicos contábeis 2009. CPC. Brasília: Conselho Federal de Contabilidade: 357-368 p. 2009.

CPC. CPC 27 Ativo Imobilizado. Pronunciamentos técnicos contábeis 2009. Brasília: Conselho Federal de Contabilidade: 540-557 p. 2010.

CPC. CPC 29 Ativo biológico e produto agrícola. 2009. Disponível em: < http://static.cpc.mediagroup.com.br/Documentos/324_CPC_29_rev\%2003.pdf >. Acesso em 19.09.2016.

FARIA, D. F.; MONTOVANI, E.; MARQUES, S. M. A contabilidade rural no desenvolvimento do agronegócio. Iniciação cientifica, Varginha-FACECA, v. 1, n. 8, p. 924. Jan./ dez. 2010. 
FIORENTIN, F. R.; OLIVEIRA, D. d. L.; SOUZA, J. A. d.; CUSTÓDIO, E. M. O. Fair value e custo histórico na produção de flores: uma proposta de mensuração pelo fluxo de caixa líquido esperado Custos e @ gronegócio on line, v. 10, n. 3, p. 145-164, 2014.

FREIRE, F. de S.; PRADO, S. S. do; MARQUES, M. de M., PEREIRA, E. M. Valor justo dos ativos biológicos: um estudo sobre a aplicabilidade do CPC 29 em um jardim zoológico. Gestão Contemporânea, Porto Alegre, ano 9, n. 12, p. 207-233, jul./dez. 2012.

GERHARDT, T. E.; SILVEIRA, D. T. Métodos de Pesquisa. Universidade Aberta do Brasil - UAB/UFRGS. 1 ${ }^{\text {a }}$ Edição, 2009.

IUDÍCIBUS, S. d.; MARTINS, E.; GELBCKE, E. R.; SANTOS, A. d. Manual de contabilidade societária: Aplicável a todas as Sociedades - De acordo com as Normas Internacionais e do CPC. $2^{\mathrm{a}}$. São Paulo: Atlas, 2013.

MARTINS, A. S., OLIVEIRA, D. de L. Reconhecimento Contábil da Degeneração de Ativos Biológicos para a Produção no Cultivo de Árvores Frutíferas. Revista de Contabilidade Contemporânea, v. 11, n. 22 p. 73-94, jan/abr. 2014.

MARTINS, V. G., MACHADO, M. A. V.; CALLADO, A. L. C. Relevância e representação fidedigna na mensuração de ativos biológicos a valor justo por empresas listadas na BM\&FBovespa. Revista de Contabilidade Contemporânea, v. 11, n. 22, p. 163-188, Jan/Abr. 2014.

OLIVEIRA, D. L., OLIVEIRA, G. D. Contabilidade Rural - Uma abordagem do Agronegócio dentro da Porteira. 2 ed. Curitiba-PR: Juruá Editora, 2015.

PRODANOV, C. C.; FREITAS, E. C.; Metodologia do trabalho científico: Métodos e técnicas da pesquisa e do trabalho acadêmico. 2. Ed. Universidade Feevale, Novo Hamburgo, 2013.

RECH, I. J.; PEREIRA, I. V. Valor justo: análise dos métodos de mensuração aplicáveis aos ativos biológicos de natureza fixa. Custos e @gronegócio on line- v.8, n. 2, Abr/Jun 2012.

SEAB - Secretaria de Estado da Agricultura e do Abastecimento. Análise da conjuntura agropecuária - avicultura de postura 2012/2013. Disponível em: http://www.agricultura.pr.gov.br/arquivos/File/deral/Prognosticos/avicultura_postura_2012_1 3.pdf. Acessado em 17/11/2015.

SILVA, R. M. da; FIGUEIRA, L. M.; PEREIRA, L T. de O. A.; RIBEIRO, M. de S. CPC 29: Uma Análise dos Requisitos de Divulgação entre Empresa de Capital Aberto e Fechado do Setor de Agronegócios. Sociedade, Contabilidade e Gestão, Rio de Janeiro, v. 8, n.1, jun/abr 2013.

SILVA FILHO, A. C. d. C. e.; MACHADO, M. A. V.; MACHADO, M. R. Custo histórico X valor justo: qual informação é mais value relevant na mensuração dos ativos biológicos? Custos e @ gronegócio on line, v. 9, n. 2, p. 27-50, 2013.

SILVA, R. L. M.; NARDI, P. C. C.; RIBEIRO, M. S. Gerenciamento de Resultados e Valorização dos Ativos Biológicos. Brazilian Business Review, v. 12, n. 4, p. 1-27, 2015 
VINCENSI, E. M. Marcação a mercado dos fundos de investimento financeiros. 2003. 123p (Mestrado profissional). Faculdade de Ciências Econômicas. Programa de Pós-Graduação em Economia, UFRGS, Porto Alegre - RS.

WANDERLEY, C. A. N.; SILVA, A. C. D.; LEAL, R. B. Tratamento contábil de ativos biológicos e produtos agrícolas: uma análise das principais empresas do agronegócio brasileiro. Revista Pensar Contábil, v. 14, p. 53-62, 2012.

YIN, R. K. Estudo de caso: planejamento e métodos. 4. ed. Porto Alegre: Bookman, 2010. 